Short Communication

\title{
KNUCKLE-WALKING: PRELUDE TO HOMININ BIPEDALTY OR ACQUIRED MECHANISM TO PROTECT FINGERTIPS?
}

\author{
Arunachalam Kumar \\ Professor of Anatomy, K.S. Hegde M edical Academy, Nitte University, \\ M angalore - 575 018, India \\ Correspondence: \\ Arunachalam Kumar, \\ E-mail : dean.kshema@ nitte.edu.in
}

\begin{abstract}
:
The exact period, cause and evolution of erect posture and bipedal gait in early hominids has subject of much debate among primatologists and anthropologists. This brief presentation proposes at least that one among the theories, knuckle-walking as a precursor to bipdality is probably debatable. In higher apes, which spend more time on foraging at terrestrial level and less as arboreal primates, knuckle walking may have evolved more as a nail and fingertip protective adaptation in apes.
\end{abstract}

Keywords: knuckle-walking, bipedal gait, hominin, Australopithecus, apes,

\section{Introduction:}

Erect posture and bipedality as a preferred mode for locomotion are uniquely human traits. ${ }^{1}$ M uch debate has centered round the origins, time and sequence of the hindlimb weight support and propulsion characteristic, a hominid attribute. Was the transition from a four-legged gait to a biped one a gradual or sudden? It is widely accepted among physical anthropologists that the change in mode and mechanism of propulsion was a long drawn evolutionary event. Needs and necessities, compulsions and compensations that the early hominids experienced and underwent in achieving a fair amount of mechanical efficiency and stability in locomotion required quite a few redesigning and modification in certain key elements of the skeletal system. Alteration in the center of gravity mandated by postural changes engineered osteological adaptations in the hip bones, vertebrae, sacrum and skull. Less obvious, but as significant were the changes occurring in osteo-architecture of the manus (hand).

It must be recalled here that the liberation of the pollex (thumb) and the conversion of the first carpometacarpal joint from a condylar into a saddle, enabled the thumb to be opposed to the index. The liberation of the forelimbs into performance of higher, more compulsive, and educated tasks from its hitherto chore of supporting body weight and mobility, is claimed to be the cornerstone of bipedalism and thence into the explosion of cerebration that led to the genesis of bipeds into rational homos ${ }^{4,5}$.

\section{Discussion :}

What yet remains un-solved is why or how the forelimb skeletal architecture modified into a need-based functional instrument. Going into the world the gorillas or chimpanzees, locomotion is essentially a four-limbed activity, but oddly, the forelimb in gorilla, is not held paw down, but reversed. The animal is a knuckle-walker, supporting its weight on the knuckles (Fig: $1 \& 2$ ). The digits are flexed inwards, the paw's digital pulps are held protected with the limb terminating into the fisted paw.

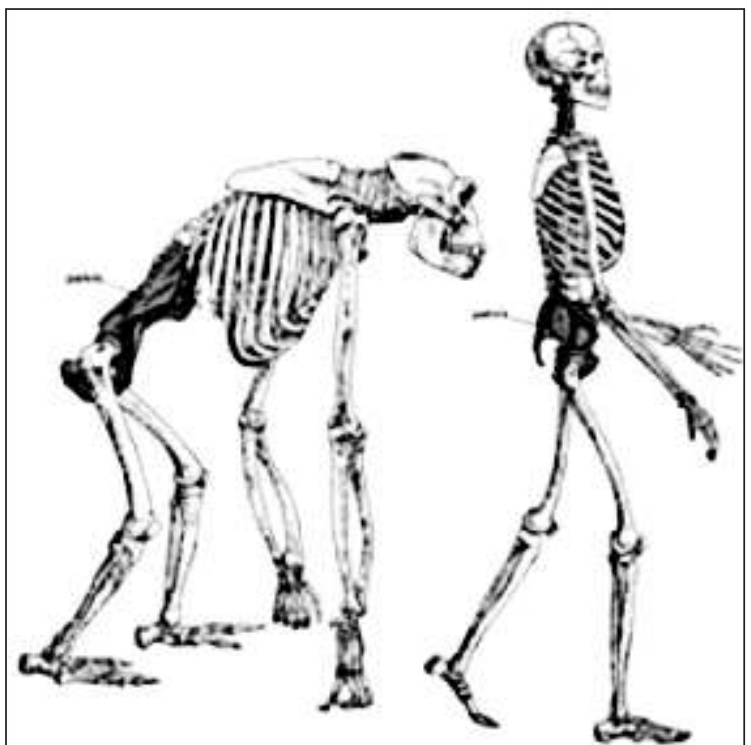

Fig: 1 Knuckle-walking ape 
Why so abruptly, did the forelimb turn inwards into a clenched fist? Why, when every quadruped walked on all four paw pads, did the gorilla decide to move on forelimb knuckles? $^{2}$

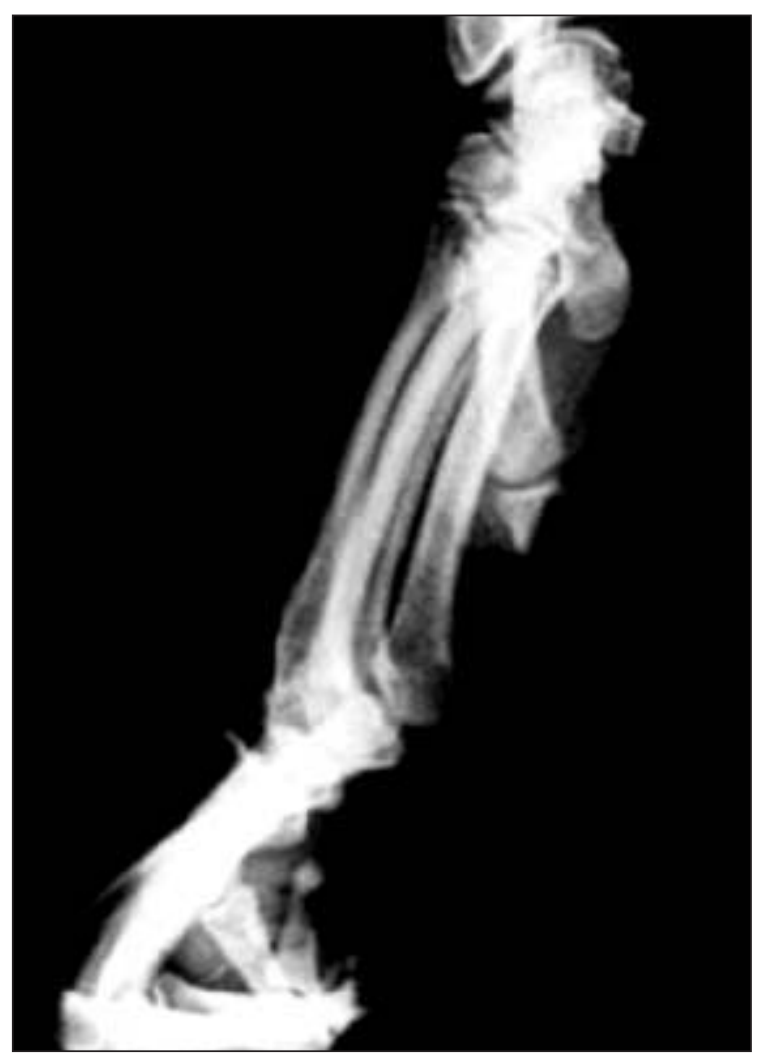

Fig: 2 Radiograph of chimp wrist

from: http://www.nature.com/news/2000/000323/full/news000323-7.htm

The change in kinematics does engender debate. Did the phalanges lengthen? Did cataclysmic embryonic cell death forming digital rays (and regression of webbing size) result in increase in functional mobility and individuality in digits? Did they, as consequence become arachnoid? Were the forelimb fingers now more prone to fingertip injuries and fingernail avulsions? Was the injury prone open padpaw, compromising the efficiency of its locomotor functions. Was the higher ape perforce to find the need to flexits digits as a fingertip protective adaptation? ${ }^{3}$

Flexion is a universally acknowledged as protective. Even an invertebrate curls itself into a posture of complete flexion when sensing danger. $M$ an too does so, even in his foetal in-utero existence. With the fore digital phalanges lengthening, and injury prone, the gorilla sought to protect their anatomically modified appendages, and protect their evolutionary acquisitions - by flexing them inwards. Now walking had to be done, on knuckles, not on the foot pads. The question now arises, did this shift over to palmar flexion, and the biomechanics of opposition evolution go hand in hand, or not? If not, then knuckle walkers and brachiators indeed form a vital link in evolution of human gait, with the flexed fist walking forming the first link in the chain that led to bipedalism. Was this the prelude to the liberation of the thumb?

Whatever be the debate, the fact remains, knuckle walking as a preferred mode of weight bearing and locomotion has long been viewed at as an odd means of propulsion, with many proponents claiming it as fore-runner of bipedal gait. It is time kinesiologists and evolutionary biologists reviewed the role attributed to knuckle walking as being prelude to development of bipedal gait, to revisit the biomechanics of hand evolution- maybe knuckle-walking was merely an adaptive finger-tip protective aid in terrestrial mobility: not as a modulation that heralded conversion of the forelimb from an essential part of quadruped gait to a dexterous instrument of 'educated' functionality: For the transition from pes to manus and thence to bipedality - factors other than knuckle walking may have been preludes.

\section{References:}

1. Arunachalam Kumar, The why of knuckle walking http://network.nature.com/groups/transcience/forum/topics/ 5454

2. Arunachalam Kumar, Shedding a tear for bipedalism: Parts | \& || http://network.nature.com/groups/transcience/forum/topics/ 5451

3. Arunachalam Kumar(2011) An overview on evolution of human erect posture, bipedal mobility \& gait Rajiv Gandhi University of Health Sciences, RGUHSJ ournal of M edical Sciences 1: 3: 35-41

4. Carvalho S, Biro D, Cunha, E, Hockings K, M cGrew CW, Richmond BG \& Matsuzawa, T, (2012) Chimpanzee carrying behaviour and the origins of human bipedality, Current Biology, Volume 22, Issue 6, R180-R181

5. Richmond BG, Begun DR, Strait DS., Origin of human bipedalism, (2001) The knuckle-walking hypothesis revisited. , Am J Phys Anthropol. Suppl., 33:70-105. 